\title{
SOME MONOTONICITY PROPERTIES OF GENERALIZED ELLIPTIC INTEGRALS WITH APPLICATIONS
}

\author{
MiaO-Kun Wang, Yu-Ming Chu and Song-Liang QiU
}

Abstract. In this paper, we present some monotonicity theorems involving the generalized elliptic integrals $\mathscr{K}_{a}(r)$ and $\mathscr{E}_{a}(r)$, and find an asymptotic property of $\mathscr{K}_{a}(r)$ when $r \rightarrow 1$. As applications, some well known results are improved.

Mathematics subject classification (2010): 33E05.

Keywords and phrases: Gaussian hypergeometric function, generalized elliptic integrals, monotonicity.

\section{REFERENCES}

[1] G. D. Anderson, S.-L. Qiu, M. K. Vamanamurthy and M. Vuorinen, Generalized elliptic integrals and modular equations, Pacific J. Math. 192 (2000), 1-37.

[2] G. D. ANDERSON, S.-L. QIU AND M. VuORINEN, Precise estimates for differences of the Gaussian hypergeometric function, J. Math. Anal. Appl. 215 (1997), 212-234.

[3] G. D. Anderson, M. K. Vamanamurthy And M. Vuorinen, Functional inequalities for hypergeometric functions and complete elliptic integrals, SIAM J. Math. Anal. 23 (1992), 512-524.

[4] G. D. Anderson, M. K. Vamanamurthy and M. Vuorinen, Conformal Invariants, Inequalities, and Quasiconformal Maps, Wiley, New York, 1997.

[5] G. D. Anderson, M. K. Vamanamurthy And M. Vuorinen, Generalized convexity and inequalities, J. Math. Anal. Appl. 335 (2007), 1294-1308.

[6] Á. BARICZ, Turán type inequalities for generalized complete elliptic integrals, Math. Z. 256 (2007), 895-911.

[7] R. W. Barnard, K. Pearce And K. C. Richards, A monotonicity property involving ${ }_{3} F_{2}$ and comparisons of the classical approximations of elliptical arc length, SIAM J. Math. Anal. 32 (2000), 403-419.

[8] B. A. BHAYO AND M. VuORINEN, On generalized complete elliptic integrals and mudular functions, Proc. Edinb. Math. Soc. 55 (2012), 591-611.

[9] B. C. Carlson, J. L. Guatafson, Asymptotic approximations for symmetric elliptic integrals, SIAM J. Math. Anal. 25 (1994), 288-303.

[10] V. Heikkala, H. Lindén, M. K. Vamanamurthy and M. Vuorinen, Generalized elliptic integrals and the Legendre $\mathscr{M}$-function, J. Math. Anal. Appl. 338 (2008), 223-243.

[11] V. Heikkala, M. K. Vamanamurthy and M. Vuorinen, Generalized elliptic integrals, Comput. Methods Funct. Theory 9 (2009), 75-109.

[12] R. KÜHNAU, Eine Methode, die Positivität einer Funktion zu prüfen, Z. Angew. Math. Mech. 74 (1994), 140-143 (in German).

[13] E. NeUman, Inequalities and bounds for generalized complete elliptic integrals, J. Math. Anal. Appl. 373 (2011), 203-213.

[14] S. Ponnus Amy And M. Vuorinen, Univalence and convexity properties of Gaussian hypergeometric functions, Rocky Mountain J. Math. 31 (2001), 327-353.

[15] S.-L. QIU, Grötzsch ring and Ramanujan's modular equations, Acta Math. Sinica 43 (2000), 283-290 (in Chinese).

[16] S.-L. QIU AND M. VUORINEN, Infinite products and the normalized quotients of hypergeometric functions, SIAM J. Math. Anal. 30 (1999), 1057-1075. 
[17] S.-L. QIU AND M. VuORINEN, Landen inequalities for hypergeometric functions, Nagoya Math. J. 154 (1999), 31-56.

[18] S.-L. QIU, M. Vuorinen, Chapter 14 Special functions in geometric function theory, Hand-Book of Complex Analysis: geometric function theory 2 (2005), 621-659.

[19] E. D. Rainville, Special Functions, MacMillan, New York, 1960.

[20] M. SAIGO AND H. M. SRIVASTAVA, The behavior of the zero-balanced hypergeometric series ${ }_{p} F_{p-1}$ near the boundary of its convergence region, Proc. Amer. Math. Soc. 110 (1990), 71-76.

[21] S. Simić AND M. Vuorinen, On quotients and differences of hypergeometric functions, J. Inequal. Appl. 2011, 2011: 141, 10 pages.

[22] S. SimiĆ AND M. VuORINEN, Landen inequalities for zero-balanced hypergeometric functions, Abstra. Appl. Anal. 2012, Article ID 932061, 11 pages.

[23] G.-D. WANG, X.-H. ZHANG AND Y.-M. CHU, Inequalities for the generalized elliptic integrals and modular functions, J. Math. Anal. Appl. 331 (2007), 1275-1283.

[24] E. T. Whittaker And G. N. Watson, A Course of Modern Analysis, 4th ed., Cambridge Univ. Press, London, 1958.

[25] X.-H. Zhang, G.-D. Wang And Y.-M. ChU, Remarks on generalized elliptic integrals, Proc. Roy. Soc. Edinburgh Sect. A 139 (2009), 417-426. 